\title{
Design and Analysis of a Cost-Effective Magnetless Multi-Phase Flux-Reversal DC-Field Machine for Wind Power Generation
}

\author{
Christopher H. T. Lee, Student Member, IEEE, K. T. Chau, Fellow, IEEE, and Chunhua Liu, Senior \\ Member, IEEE
}

\begin{abstract}
This paper proposes a new four-phase flux-reversal DC-field (FRDC) machine for the wind power generation applications. The key distinction of the proposed generator is to artfully design its stator pole and winding arrangement, in a way imitating the permanent-magnet (PM) configurations on the profound FRPM machine has. Hence, the proposed FRDC generator can provide the bipolar flux-linkage patterns and achieve performances similarly as the high-quality FRPM generators do. The proposed generator can regulate its controllable DC-field winding to vary its flux density effectively. Thus, it can achieve the constant-output-voltage characteristics at different situations, in order to extend the battery life and to protect the power grid system. Without installation of any highcost PM materials, the proposed magnetless FRDC generator can achieve better cost-effectiveness than its PM counterparts do. The key performances of the proposed wind power generator are thoughtfully analyzed by the finite element method (FEM) while the experimental prototype is also setup for verifications.
\end{abstract}

Index Terms-Magnetless, multi-phase, flux-reversal, wind power generation.

\section{INTRODUCTION}

$\mathrm{E}$ NERGY crisis and environmental pollution have become the worrying problems since the last few decades, while the renewable wind power generation is one of the most probable solutions to relieve the situations [1]-[3]. Generally speaking, the wind power generations can be classified into two major categories, namely the constant-speed constantfrequency (CSCF) wind power generation and the variablespeed constant-frequency (VSCF) wind power generation [4][6]. Without implementing any power converters, the CSCF type benefits from the absolute predominance of simple system structure and high robustness [7]. Nevertheless, in the CSCF mechanism, the system has to disconnect the response with the wind speed such that the turbine speed has to be confined in a limited range. Not surprisingly, the CSCF system has to bear the high mechanical stress problems and ends up with relative low efficiency.

This work was supported by the Hong Kong Research Grants Council, Hong Kong Special Administrative Region, China (Project No. 17200614).

The authors are with the Department of Electrical and Electronic Engineering, The University of Hong Kong, Pokfulam, Hong Kong (e-mail: ktchau@eee.hku.hk).

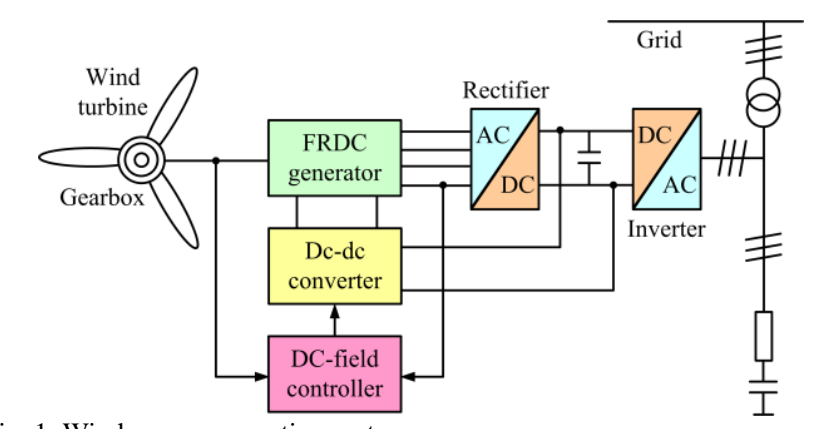

Fig. 1. Wind power generation system.

To improve the situation from the CSCF system, the VSCF type has been developed accordingly. With the support of the power electronics, the VSCF system can vary its turbine speed in accordance to the wind speed, in order to capture the maximum wind energy for power generation [8]-[10]. Undoubtedly, the VSCF type can provide higher overall efficiency compared with the CSCF does. As the soul of the VSCF system, the electric machines have to fulfill several criteria, including high efficiency level, high power density, high controllability, wide-speed operating range, and brushless operation [11], [12].The doubly salient permanent-magnet (DSPM) machines, which can achieve most of the mentioned goals, have been actively developed [13]-[15]. Particularly, the flux-reversal PM (FRPM) machine, which offers the bipolar flux-linkage and thus higher power density, has attracted more attentions recently [16]-[18]. However, similar to the well-developed DSPM machines, the FRPM machine also has to tackle two vital problems, namely the high PM material cost and the uncontrollable PM flux densities [19][23]. To get round these structural problems, the doubly salient DC-field (DSDC) machine was suggested [24]. By replacing the PM materials with the independent DC-field winding, the DSDC machine can enjoy the benefits of higher costeffectiveness and better flux controllability [25]. Yet, the development of the FRDC machine is still absent.

This paper aims to implement the new modulated stator pole structure for the specific winding arrangement, to emulate the PM configuration that existing in the FRPM machines. Hence, a new magnetless four-phase FRDC machine is proposed, purposely for the wind power generation system. The machine performances are analyzed by the finite element method (FEM), while the experimental results are also provided to verify the proposed idea. 


\section{SYSTEM ARCHITECTURE}

Fig. 1 shows the wide-speed range wind power generation system configuration. To be specific, it consists of seven key elements: (i) a wind turbine equipped with gearbox to capture the wind power, (ii) the proposed FRDC machine to converse the electromechanical energy, (iii) a full-bridge rectifier to provide the ac-dc conversion, (iv) a battery to store the generated energy, (v) an inverter to provide the dc-ac conversion to the power grid, (vi) a DC-field controller to feedback the DC-field current signal, and (vii) a buck converter to regulate the dc voltage for flux regulation.

Based on the Betz theory, the mechanical power captured by the wind turbine can be described as [6]

$$
P_{\text {mech }}=\frac{1}{2} C_{p} \rho v_{\omega}^{3} A
$$

where $C_{p}$ is the coefficient of wind power conversion factor with a typical value of 0.4 or below, $\rho$ is the air density, $v_{\omega}$ is the wind velocity, and $A$ is the swept area of the wind-turbine rotor. The value of $C_{p}$ is a function based on the ratio of the blade tip speed to the wind speed $\beta$, and defined as

$$
\beta=\frac{\omega R}{v_{\omega}}
$$

where $R$ is the radius of the blades and $\omega$ is the rotational speed of the wind-turbine shaft. For a specific value $\beta_{\max }$, the power conversion factor $C_{p}$ can reach to a single maximum in order to capture the maximum mechanical power from the wind speed. Undoubtedly, the turbine speed should vary along with the wind speed to maximize its total power generation. With turbine runs at the $\beta_{\max }$, the maximum generated power can then be described as

$$
P_{\text {mech }}=\frac{1}{2}\left(C_{p \max } \pi R^{2} \rho\right) v_{\omega}^{3}
$$

According to equation (2) and (3), the maximum generated power can be further described as

$$
P_{\text {mech }}=\frac{1}{2}\left(\frac{C_{p \max } \pi R^{5} \rho}{\beta_{\max }^{3}}\right) \omega^{3}
$$

It should be noted that the turbine speed of the wind generator is typical around $1000 \mathrm{rpm}$ at the normal wind situation [8].

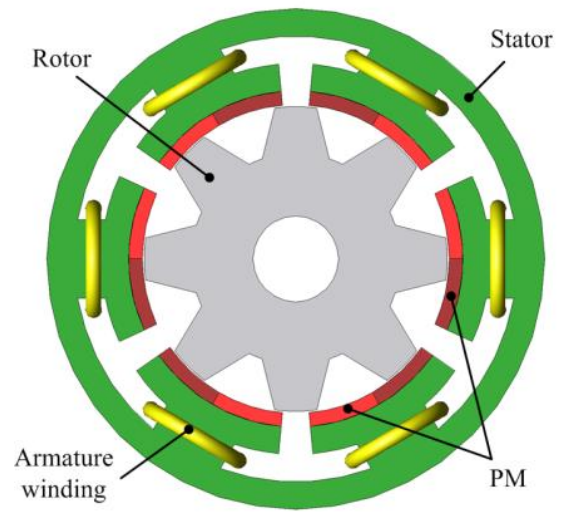

(a)

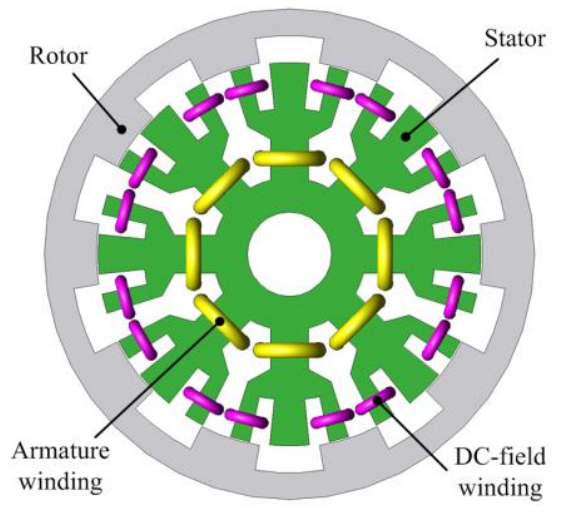

(b)

Fig. 2. Machine structures: (a) FRPM type. (b) Proposed FRDC type.

\section{PROPOSED FRDC MACHINE}

\section{A. Proposed Machine Structure}

The topologies of the traditional FRPM machine and the proposed four-phase FRDC machine are shown in Fig. 2. Because the proposed FRDC machine is developed based on the typical FRPM machines, its design equations such as the pole arrangements can be extended from that of the traditional FRPM machines, and as shown below [17]

$$
\left\{\begin{array}{l}
N_{s p}=2 m k \\
N_{s e}=N_{s p} p_{s} \\
N_{r}=N_{s e}+2 k
\end{array}\right.
$$

where $N_{s p}$ is the number of actual stator poles, $p_{s}$ the flux polepair on the stator tooth, $N_{s e}$ the apparent stator poles, $N_{r}$ the rotor poles, $m$ the armature phases and $k$ any integer. The fundamental design combinations of the proposed FRDC machine are categorized in Table I. Based on the considerations of the stability and cost-effectiveness, the fourphase topology is preferred [25]. Meanwhile, to ease the manufacturing complexity, the minimum number of flux polepairs should be chosen. By taking these concerns into consideration, the following combination is selected: $m=4, k$ $=1, N_{s p}=8, p_{s}=1, N_{s e}=8$, and $N_{r}=10$, as the proposed structure for the FRDC machine.

The traditional FRPM machine equips the PMs of alternating polarities on each of its stator pole, and hence reversing the signs of its flux-linkage in accordance to its rotor positions [16]. The proposed FRDC machine purposely allocates its DC-field windings in the modulated stator slots in a way to imitate the FRPM configuration, thus offering the same reversing flux-linkage pattern as the FRPM machines do. To achieve it, each of the stator pole is modulated as a 3-tooth per stator pole machine as indicated in Fig. 2. When the FRDC rotates its rotor from position 1 to 2 , the polarities of its fluxlinkages interchange accordingly, as shown in Fig. 3. With the bipolar flux-linkage characteristic, the proposed FRDC generator enjoys the higher power density as compared with its unipolar flux-linkage counterpart does [17], [21]. 

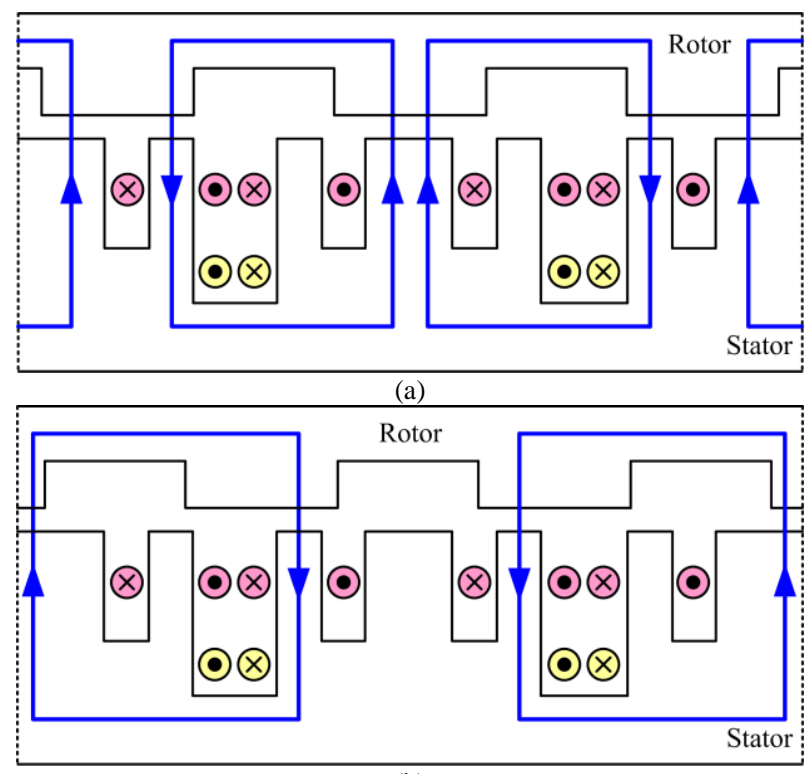

(b)

Fig. 3. Flux patterns of FRDC machine: (a) Position 1. (b) Position 2.

TABLE I

Fundamental Design Combinations of the Proposed FRDC Machine

\begin{tabular}{cccccc}
\hline \hline $\boldsymbol{m}$ & $\boldsymbol{k}$ & $\boldsymbol{N}_{\boldsymbol{s} \boldsymbol{p}}$ & $\boldsymbol{p}_{\boldsymbol{s}}$ & $\boldsymbol{N}_{\boldsymbol{s} \boldsymbol{e}}$ & $\boldsymbol{N}_{\boldsymbol{r}}$ \\
\hline 3 & 1 & 6 & 1 & 6 & 8 \\
3 & 2 & 12 & 1 & 12 & 16 \\
3 & 1 & 6 & 2 & 12 & 14 \\
4 & 1 & 8 & 1 & 8 & 10 \\
4 & 2 & 16 & 1 & 16 & 20 \\
\hline \hline
\end{tabular}

\section{B. Selection of the Multi-phase Topologies}

The no-load electromagnetic force (EMF) waveforms may exhibit infinite many patterns in reality, while all these waveforms can be roughly classified into two major categories, namely the sinusoidal-like waveform and the trapezoidal-like waveform [8]. Meanwhile, the no-load EMF patterns can be regulated by the machine structure as well as the pole-pair arrangement.

When the no-load EMF $e_{s}$ and phase current $i_{s}$ are in phase with sinusoidal patterns, the average output power $P_{s}$ can be expressed as

$$
P_{s}=\frac{1}{\pi} \int_{0}^{\pi} e_{s}(\omega t) i_{s}(\omega t) d(\omega t)=\frac{1}{2} E_{s} I_{s}
$$

where $E_{s}$ and $I_{s}$ are the amplitudes of the no-load EMF and phase current with sinusoidal-like waveforms, respectively. Similarly, when the no-load EMF $e_{t}$ and phase current $i_{t}$ are in phase with trapezoidal patterns, the average output power $P_{t}$ can be expressed as

$$
P_{t}=\frac{1}{\pi} \int_{0}^{\pi} e_{t}(\omega t) i_{t}(\omega t) d(\omega t)=\frac{1}{3}\left(2 k_{t}+\frac{6}{m}\right) E_{t} I_{t}
$$

where $k_{t}$ is the inclining slopes of the trapezoidal waveform, $E_{t}$ and $I_{t}$ are the amplitudes of the no-load EMF and phase current with trapezoidal-like waveforms, respectively. By combing the equations (6) and (7), the power ratio of the sinusoidal to trapezoidal types can be further deduced as

$$
\frac{P_{s}}{P_{t}}=\left(\frac{3 m}{4 k_{t} m+12}\right)\left(\frac{E_{s} I_{s}}{E_{t} I_{t}}\right)
$$

The rms no-load EMF ratio of the sinusoidal to trapezoidal patterns can be described as

$$
\frac{E_{s}}{E_{t}}=\frac{\pi}{2}\left(\frac{k_{t} m+2}{m}\right)
$$

Similarly, the rms phase current ratio of the sinusoidal to trapezoidal patterns can be described as

$$
\frac{I_{s}}{I_{t}}=\sqrt{\frac{4 k_{t} m+12}{3 m}}
$$

By combining equations (8), (9) and (10), the power ratio can be further deduced as

$$
\frac{P_{t}}{P_{s}}=\frac{4 m}{\left(k_{t} m+2\right) \pi} \sqrt{\frac{k_{t} m+3}{3 m}}
$$

In the ideal case, the inclining slopes of the trapezoidal waveform should be infinite, leading to achieving the square patterns, ie: $k_{t}=0$. By taking this criterion into consideration, the power ratios at different phases are calculated and categorized in Table II. According to the results, it can be shown that starting from $m=3$, the trapezoidal-like, or squarelike waveform generators can provide higher output powers than the sinusoidal-like waveform counterparts do. This situation becomes even more obvious when it comes to higher phases. Therefore, the FRDC generator, which inherits the trapezoidal-like no-load EMF waveform, is more preferable to adopt the multi-phase topologies.

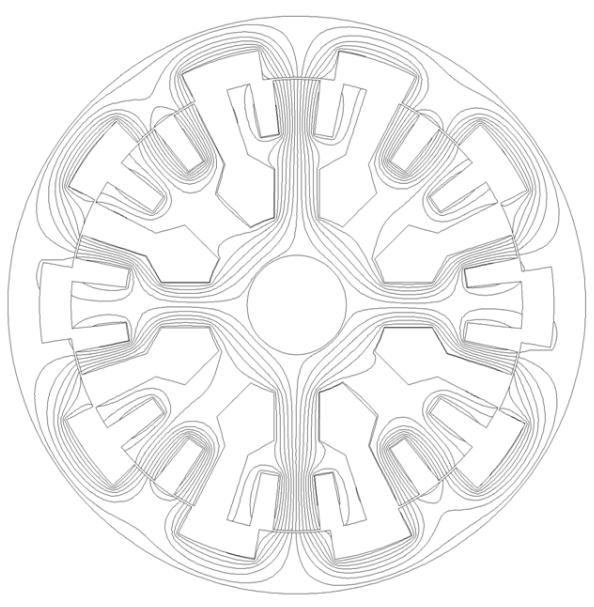

Fig. 4. Magnetic field distributions of the proposed FRDC machine.

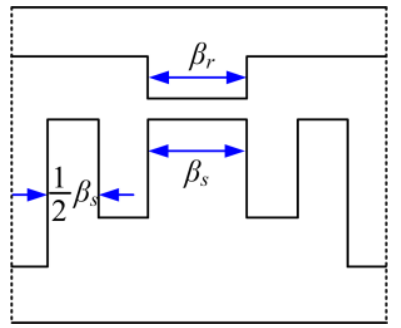

(a)

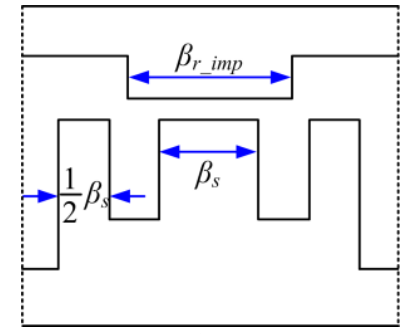

(b)
Fig. 5. Topologies of the modulated stator and rotor poles: (a) Primitive $\beta_{r}$. (b) Improved $\beta_{r_{-} i m p}$. 


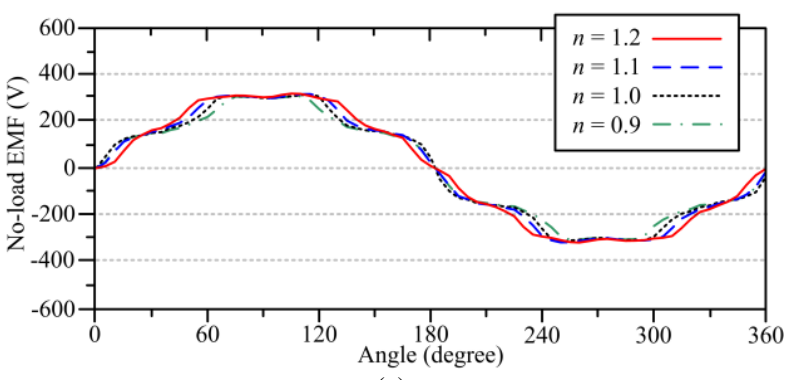

(a)

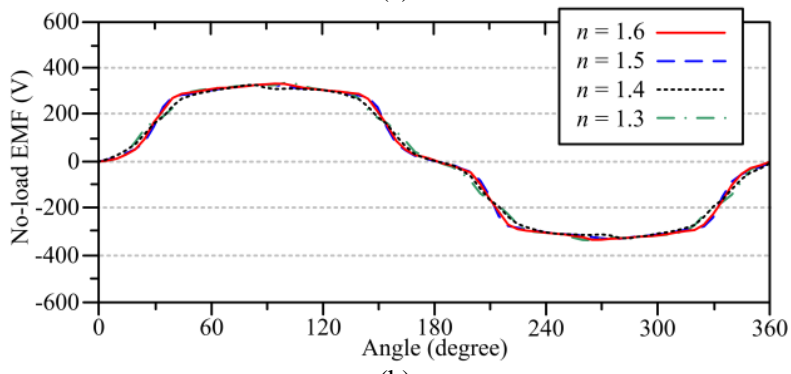

(b)

Fig. 6. No-load EMF waveforms under different pole-arc ratios: (a) $n=0.9-$ 1.2 (b) $n=1.3-1.6$.

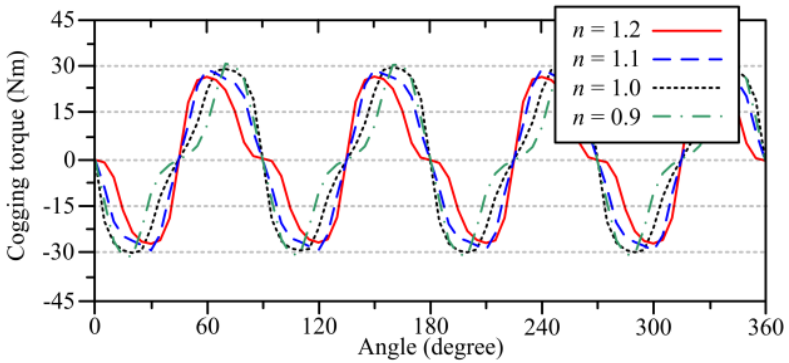

(a)

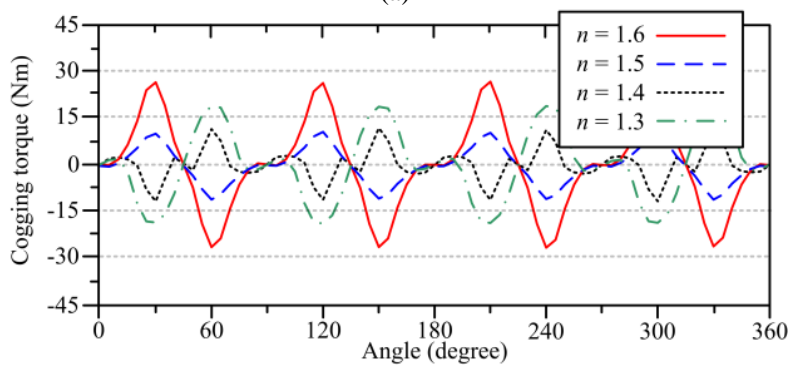

(b)

Fig. 7. Cogging torques under different pole-arc ratios: (a) $n=0.9-1.2$ (b) $n$ $=1.3-1.6$.

TABLE II

Power Ratio of Trapezoidal-Type to Sinusoidal-Type

\begin{tabular}{c|cccccc}
\hline \hline $\boldsymbol{m}$ & 1 & 2 & 3 & 4 & 5 & 6 \\
\hline $\boldsymbol{P}_{\boldsymbol{t}} / \boldsymbol{P}_{\boldsymbol{s}}$ & 0.64 & 0.90 & 1.10 & 1.27 & 1.42 & 1.56 \\
\hline \hline
\end{tabular}

\section{Generator Performance Analysis}

\section{A. Electromagnetic Field Analysis}

The electromagnetic field analysis has been one of the most accurate and convenient tools to study electric machine performances for many years. In general, it can be classified into two major categories, namely the analytical field calculation [26] and the numerical field calculation [27]. To perform the machine modeling, the electromagnetic field equations are governed by [6]

$$
\left\{\begin{array}{l}
\Omega: \frac{\partial}{\partial x}\left(v \frac{\partial A}{\partial x}\right)+\frac{\partial}{\partial y}\left(v \frac{\partial A}{\partial y}\right)=-\left(J_{z}+J_{f}\right) \\
\left.A\right|_{S}=0
\end{array}\right.
$$

where $\Omega$ is the field solution region, $A$ and $J_{z}$ the z-direction components of vector potential and current density, respectively, $J_{f}$ the equivalent current density of the excitation field, $S$ the Dirichlet boundary, and $v$ the reluctivity. Meanwhile, the equivalent circuit equation during generation is described as

$$
\left(R+R_{L}\right) i_{s}+\left(L+L_{L}\right) \frac{d i}{d t}-\frac{l}{s} \iint_{\Omega} \frac{\partial A}{\partial t} d \Omega=0
$$

where $R$ is the winding resistance, $R_{L}$ the load resistance, $L$ the end winding inductance, $L_{L}$ the load inductance, $l$ the axial length, and $s$ the conductor area of each turn of phase winding. The FEM is applied to analyze the machine performances of the proposed FRDC generator and the JMAG-Designer is employed as the magnetic solver to perform the FEM. The magnetic field distribution of the proposed generator at noload condition is shown in Fig. 4. The result shows that the flux distributions of the proposed FRDC generator are well balanced and also align with the theoretical expectations as shown in Fig. 3.

\section{B. Pole-Arc Improved Design}

In order to avoid the magnetic saturation, the values of the modulated stator tooth width $\beta_{s}$ and the rotor pole-arc $\beta_{r}$ should be well-tuned and confirmed with a particular value. Since the middle modulated stator tooth converges two balanced fluxes from both sides, its tooth width should be twice larger than that of the sided-tooth. At the primitive stage, the rotor pole-arc $\beta_{r}$ is set equal to the value of $\beta_{s}$, ie: $\beta_{r}=\beta_{s}$, as shown in Fig. 5(a). Meanwhile, the $\beta_{r}$ can be fine-tuned by improving the pole-arc ratio as described with the following expression: $\beta_{r_{-} i m p}=n \beta_{s}$, as shown in Fig. 5(b). The variations of the no-load EMF according to the pole-arc ratio, $n$ are shown in Fig. 6. As previously discussed, the more trapezoidal-like no-load EMF waveform with well-balanced pattern is more desirable for the wind power generation, and hence the pole-arc ratio should be selected in the range of $n=$ 1.4 to 1.6 .

To confirm the pro-arc ratio with the most improved performance, the cogging torque is also studied and its waveforms under different pole-arc ratios are shown in Fig. 7. In the case when $\beta_{r}=\beta_{s}$, i.e., $n=1.0$, the peak value of the cogging torque is approximately $29.2 \mathrm{Nm}$. When the pole-arc ratio is set to be $n=1.5$, the cogging torque will then be minimized to $11.3 \mathrm{Nm}$, which is only $6.28 \%$ of its rated torque. This particular cogging torque value is within the acceptable range, as compared with the commonly employed PM candidates [11]. In general, the lower the cogging torque value, the better the machine performances. Hence, it can be confirmed that the proposed generator has been improved with the pole-arc ratio at $\beta_{r_{-} i m p}=1.5 \beta_{s}$. 


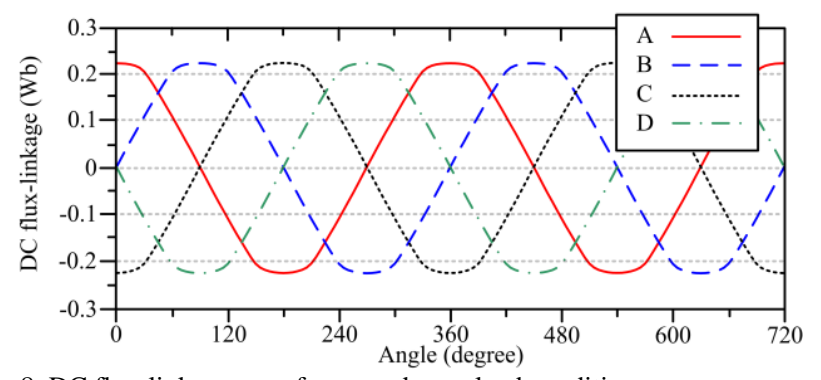

Fig. 8. DC flux-linkage waveforms under no-load condition.

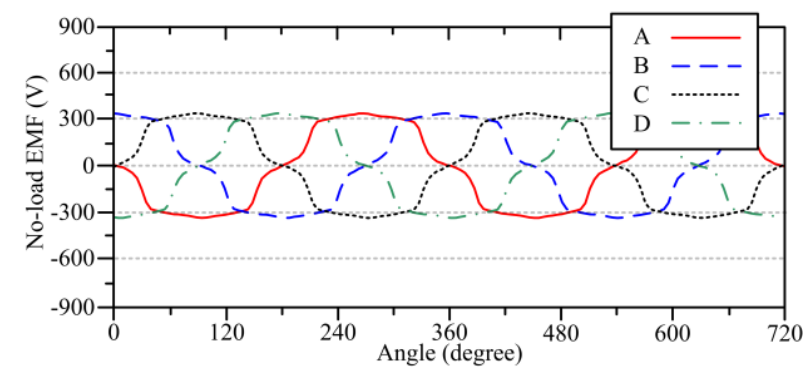

Fig. 9. No-load EMF waveforms under operating speed of $900 \mathrm{rpm}$.

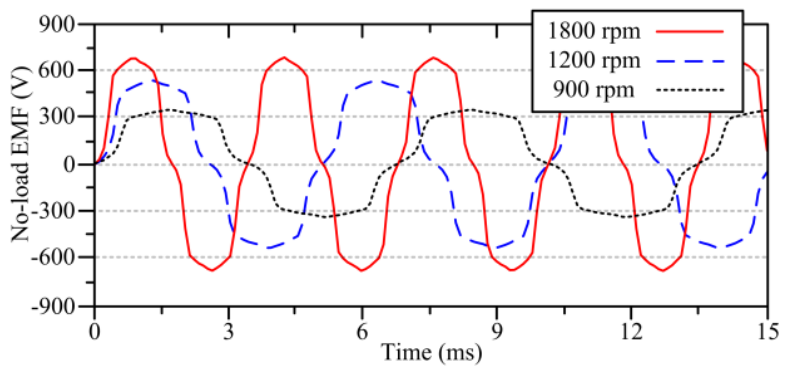

(a)

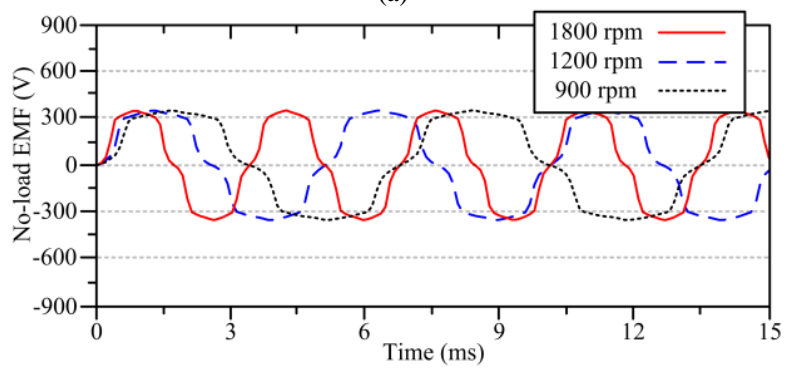

(b)

Fig. 10. No-load EMF waveforms under various operating speeds: (a) Without flux regulation. (b) With flux regulation.

TABLE III

Key Design Data of the Proposed Machines

\begin{tabular}{lccc}
\hline \hline Items & \multicolumn{2}{c}{ FRPM } & FRDC \\
\hline Rotor outside diameter & $448.0 \mathrm{~mm}$ & $448.0 \mathrm{~mm}$ \\
Rotor inside diameter & $353.0 \mathrm{~mm}$ & $353.0 \mathrm{~mm}$ \\
Stator outside diameter & \multicolumn{2}{c}{$350.0 \mathrm{~mm}$} & $350.0 \mathrm{~mm}$ \\
Stator inside diameter & \multicolumn{2}{c}{$76.0 \mathrm{~mm}$} & $76.0 \mathrm{~mm}$ \\
No. of rotor poles & 8 & 10 & 10 \\
No. of actual stator poles & 6 & 8 & 8 \\
No. of pole-pairs on stator pole & 1 & 1 & 1 \\
No. of modulated stator tooth & \multicolumn{2}{c}{$\mathrm{N} / \mathrm{A}$} & 3 \\
Rotor pole arc & $22.0^{\circ}$ & $18.0^{\circ}$ & $18.0^{\circ}$ \\
Stator (modulated) pole arc & $48.0^{\circ}$ & $36.0^{\circ}$ & $12.0^{\circ}$ \\
Airgap length & \multicolumn{2}{c}{$1.5 \mathrm{~mm}$} & $1.5 \mathrm{~mm}$ \\
Stack length & $280.0 \mathrm{~mm}$ & $280.0 \mathrm{~mm}$ \\
No. of armature phases & 3 & 4 & 4 \\
No. of turns per armature coil & 1008 & 912 & 456 \\
\hline
\end{tabular}

\section{Proposed FRDC Performance Analysis}

The DC flux-linkage waveforms of the proposed FRDC machine at no-load condition are shown in Fig. 8. The result shows the proposed machine obtains the bipolar DC fluxlinkage patterns, which behaves similarly as the traditional FRPM machine does. In addition, the simulation results show the proposed generator obtains the four-phase flux-linkage pattern without noticeable distortion. Hence, these results verify the proposed machine structure and the winding arrangement are correct.

The no-load EMF waveforms of the proposed FRDC machine under the operating speed of $900 \mathrm{rpm}$ are shown in Fig. 9. It can be shown that the no-load EMF waveforms are well-balanced with the trapezoidal-like pattern. Furthermore, the no-load EMF waveforms at various speeds under two conditions, namely without and with flux regulations are shown in Fig. 10(a) and Fig. 10(b), respectively. To illustrate the no-load EMF waveforms under different operating speeds as well as different frequencies, the waveforms in Fig. 10 are purposely plotted against time, instead of angle. Undoubtedly, without any DC-field flux regulations, the generated voltages vary along with different operating speeds. These varying output voltages are not desirable for the wind power generation because these fluctuating voltages may exceed the system threshold value and damage the whole system. On the other hand, with the support of the DC-field control, the output voltages can be maintained in a certain value over the widespeed ranges.

\section{Comparison with FRPM Machines}

To manifest the merits of the proposed magnetless fourphase FRDC machine, the well-developed FRPM machines, namely the three-phase FRPM and four-phase FRPM machines are included for comparisons. To offer the fair comparison, all the generators obtain the same machine dimensions, namely the outside diameters, stack lengths, airgap lengths, and winding fill factors. The corresponding key design data of all machines are listed in Table III.

With the application of the FEM, the performances of all machines are calculated and summarized in Table IV. In particular, the power densities of the three-phase FRPM, the four-phase FRPM, and the proposed FRDC generators are found to be $1.98 \mathrm{MW} / \mathrm{m}^{3}, 2.10 \mathrm{MW} / \mathrm{m}^{3}$ and $0.71 \mathrm{MW} / \mathrm{m}^{3}$, respectively. As discussed in Section III, in the higher number of armature phase situations, the trapezoidal-like no-load EMF generators can result higher output powers than that of the sinusoidal-like counterparts. Hence, the FR generators, which inherit the trapezoidal-like no-load EMF waveforms with the four-phase topology, can offer higher power density than that of the three-phase one. The FEM results verify the theoretical expectation in which the four-phase FRPM generator can provide higher output power that of the three-phase one, and hence illustrating the merit of the multi-phase FR generators.

By employing the high power density PM materials for field excitations, the FRPM machines can offer relatively higher power densities, as compared with the proposed magnetless FRDC counterpart. However, the PM generators suffer from the uncontrollable flux problem, and hence the PM candidates may overcharge the battery or even damage the wind power 
system at some strong wind situations. In addition, the supply of the PM materials is limited and floating, leading to the raised material costs [25].

The proposed magnetless generator undoubtedly suffers from the shortcomings of lower power density, yet a more comprehensive comparison among generators should consider flux controllability and cost-effectiveness. By utilizing the DCfield winding for excitation, the proposed FRDC machine can eliminate the high-cost PM materials, and thus accomplishing the desired performance regarding its high flux controllability and effective cost, as compared with its counterparts. Hence, it can be expected that the proposed magnetless candidate may demonstrate promising potential in the wind power generation industry

TABLE IV

Permanent-Magnet and Magnetless Generator Comparisons

\begin{tabular}{lccc}
\hline \hline Items & \multicolumn{2}{c}{ FRPM } & FRDC \\
\hline No. of armature phases & 3 & 4 & 4 \\
Power & $58 \mathrm{~kW}$ & $64 \mathrm{~kW}$ & $22 \mathrm{~kW}$ \\
Power density & $1.98 \mathrm{MW} / \mathrm{m}^{3}$ & $2.10 \mathrm{MW} / \mathrm{m}^{3}$ & $0.71 \mathrm{MW} / \mathrm{m}^{3}$ \\
Flux controllability & Low & Low & High \\
Material cost & $1245 \mathrm{USD}$ & $1398 \mathrm{USD}$ & $308 \mathrm{USD}$ \\
Cost-effectiveness & $46.6 \mathrm{~W} / \mathrm{USD}$ & $45.8 \mathrm{~W} / \mathrm{USD}$ & $71.4 \mathrm{~W} / \mathrm{USD}$ \\
\hline
\end{tabular}

\section{EXPERIMENTAL VERIFICATIONS}

To verify the proposed idea, an experimental setup for the proposed FRDC generator is established and as shown in Fig. 11. In order to perform sensible and practical experiments in the laboratory, the power level of the prototype is scaled down on purpose. Hence, the measured results are reduced proportionally, as compared with the simulated one.

The measured no-load EMF waveforms of the proposed FRDC generator under the operating speed of $900 \mathrm{rpm}$ are shown in Fig. 12. As illustrated, the measured waveforms are slightly different from the simulated results as shown in Fig. 9, and the differences are typically caused by the manufacturing imperfection. Meanwhile, the rms values of the waveforms still well agree with the theoretical ones, and hence the discrepancies are believed to be acceptable. In addition, the measured no-load EMF waveforms under the higher speed of $1800 \mathrm{rpm}$, while without and with the flux regulating controls, are shown in Fig. 13(a), and Fig. 13(b), respectively. By purposely regulating the DC-field excitation, the proposed wind power generation system can maintain its generated voltage at the same level over the wide-speed ranges, as aligning with the theoretical results in Fig. 10.

Through the ac-dc rectification, the generated voltage is rectified to give out the DC charging voltage and load current, as shown in Fig. 14. The rectified DC output can be connected to the battery as the energy storage, and the stored energy can then be transferred to the power grid after the dc-ac conversion performed by the inverter. Furthermore, the corresponding variations of the measured DC voltage with respect to the operating speed at no-load, without and with flux regulations, are shown in Fig. 15. The results confirm that the wind power generation system equipped with the proposed FRDC machine can utilize its flux-controlled capability to keep the DC charging voltages at the certain level, and hence extending the battery life cycle and protecting the whole system. In addition, the DC charging performances of the proposed system under the load conditions are also analyzed. The corresponding variations of the measured DC charging voltage characteristics under the operating speed of $900 \mathrm{rpm}$ with respect to the load current, without and with flux regulations, are shown in Fig. 16. Not surprisingly, the DC charging voltages can be once again maintained at the pre-assigned level. Hence, the results further exemplify the proposed FRDC generator can behave as a constant-output-voltage generator at the wide ranges of wind speeds and load currents, which is particularly favorable for the modern wind power generation applications.

Finally, the system efficiencies are measured under different operating speeds with different load currents, as shown in Fig. 17. It can be found that the efficiencies can be kept at high standards over a wide range of speed with different load currents. To be specific, the efficiency under the speed of 1500 rpm with load current of $1.0 \mathrm{~A}$ is around $83.5 \%$. The proposed FRDC machine can achieve comparable efficiencies as compared with the profound PM counterparts do, whose efficiencies are around $80 \%$ [8].

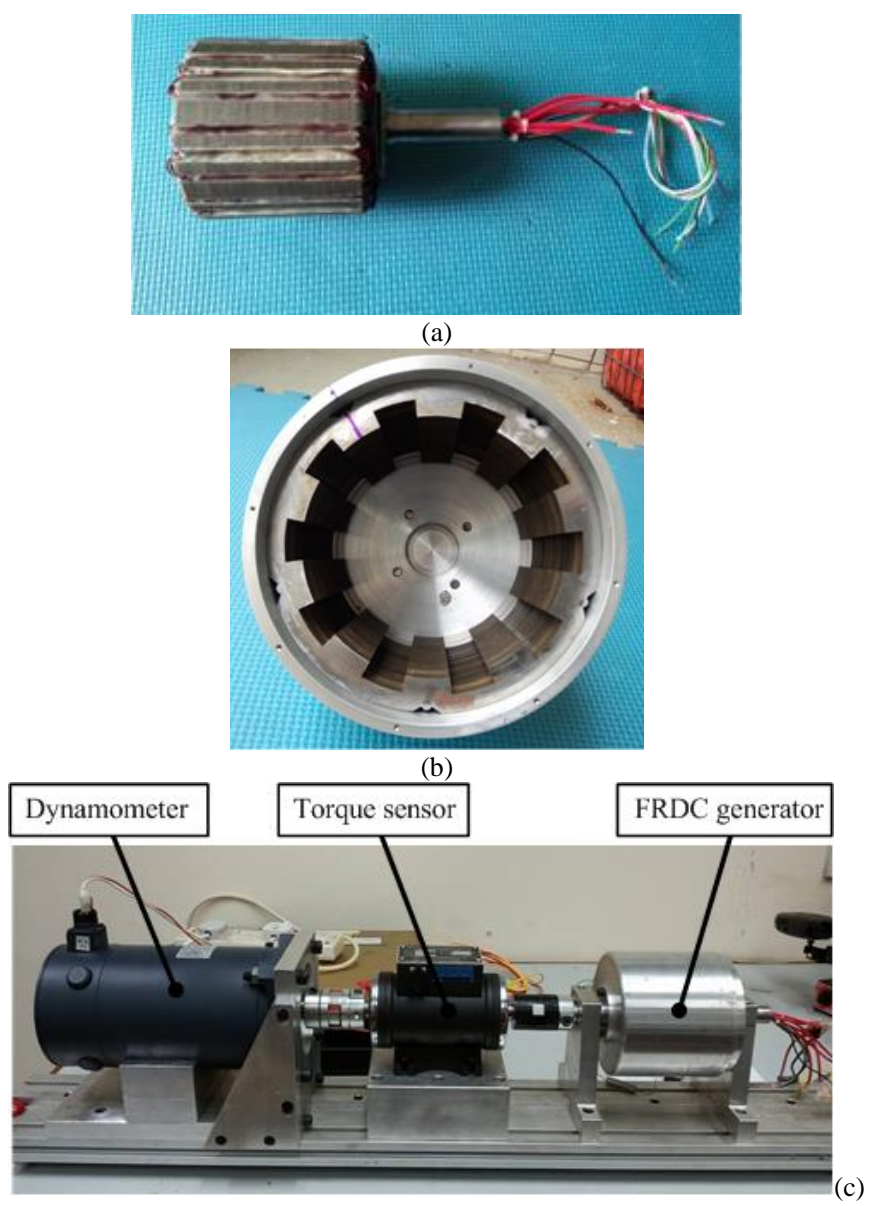

Fig. 11. Experimental setup: (a) FRDC stator segment. (b) FRDC rotor segment. (c) Test bed. 


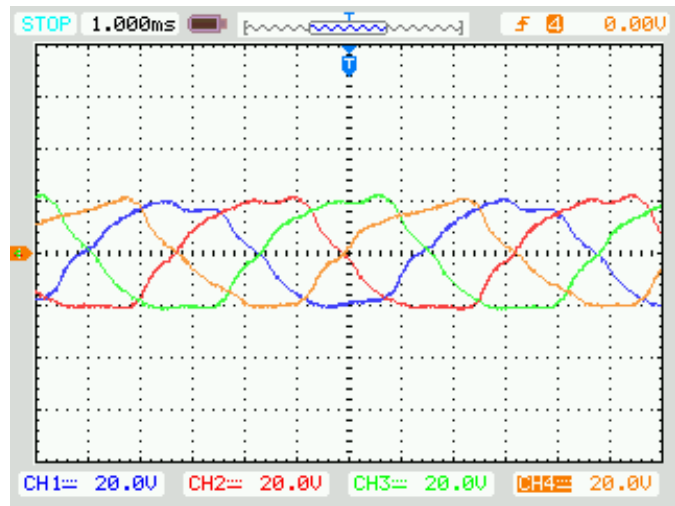

Fig. 12. Measured no-load EMF waveforms at $900 \mathrm{rpm}$.

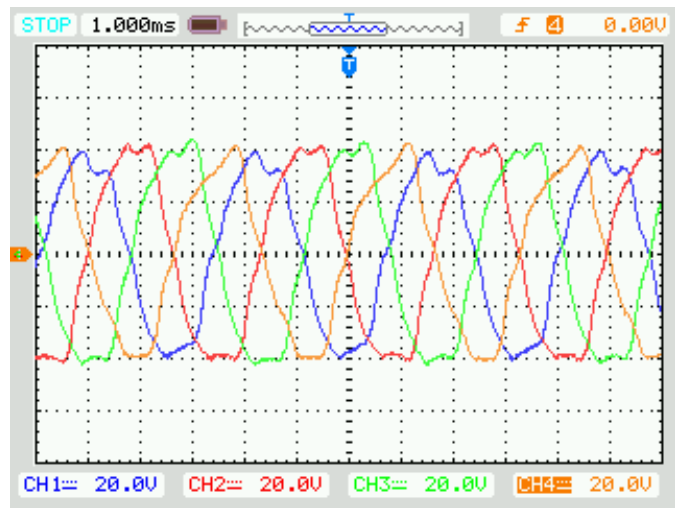

(a)

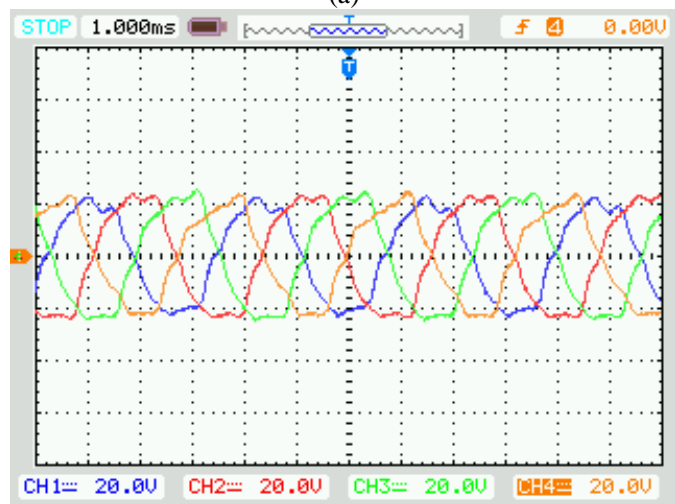

(b)

Fig. 13. Measured no-load EMF waveforms at 1800 rpm: (a) Without flux regulation. (b) With flux regulation.

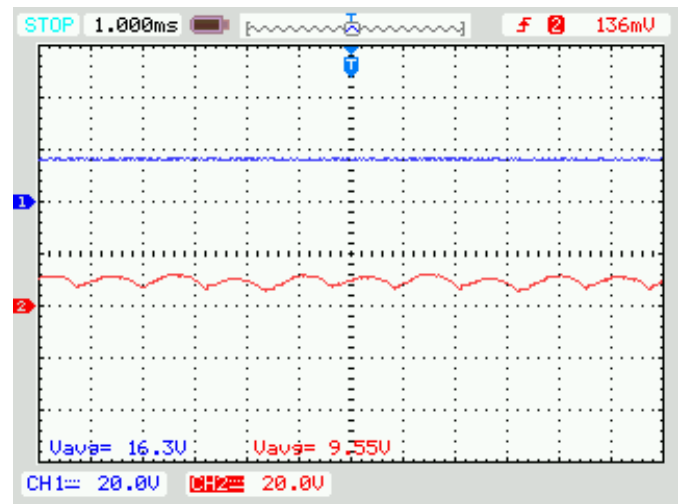

Fig. 14. Measured DC charging voltage (Trace 1) and load current (Trace 2).

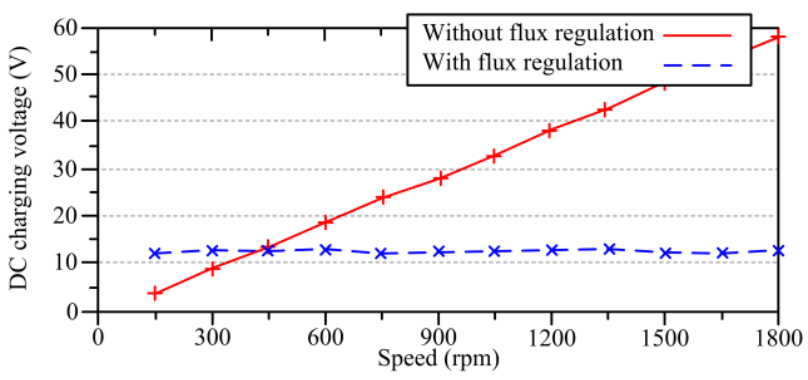

Fig. 15. Measured charging voltage characteristics versus speed at no load.

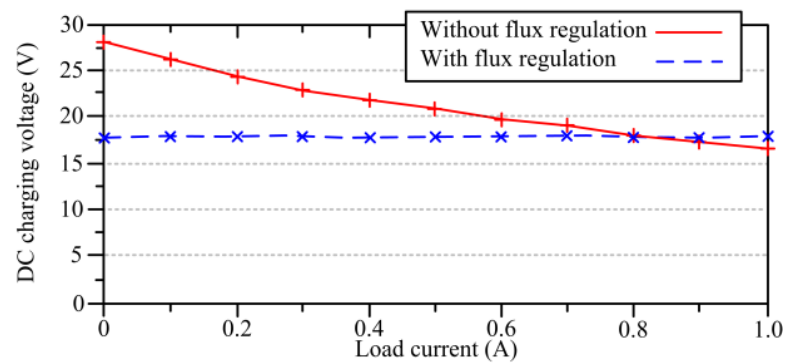

Fig. 16. Measured charging voltage characteristics versus load current.

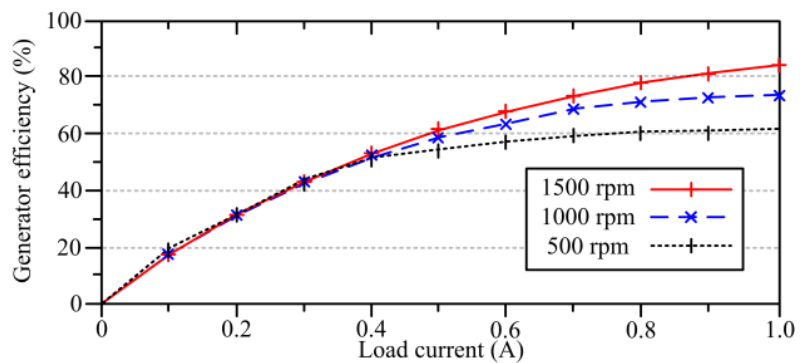

Fig. 17. Measured efficiencies versus load current at different speeds.

\section{CONCLUSION}

This paper introduces a new four-phase FRDC generator for the wind power generation applications. The key of the proposed machine is to purposely modulate the stator pole in a way to imitate the FR patterns, hence allowing the machine to behave similarly as the FRPM machine does. By utilizing the controllable DC-field winding, the proposed FRDC generator can control its airgap flux densities, thus achieving the constant-output-voltage charging characteristics under different conditions. With the magnetless structure, the proposed FRDC machine enjoys the predominance of costadvantage compared with its PM counterparts. Both the FEM analysis and experimental verifications have confirm the feasibility of the proposed wind power generation system.

\section{REFERENCES}

[1] J. P. Barton, and D. G. Infield, "Energy storage and its use with intermittent renewable energy," IEEE Trans. Energy Convers., vol. 19, no. 2, pp. 441-448, Jun. 2004.

[2] F. M Hughes, O. Anaya-lara, N. Jenkins, and G. Strbac, "Control of DFIG-based wind generation for power network support," IEEE Trans. Power Syst., vol. 20, no. 4, pp. 1958-1966, Nov. 2005.

[3] K. T. Chau, W. Li, and C. H. T. Lee, "Challenges and opportunities of electric machines for renewable energy," Prog. Electromagn. Res. B, vol. 42, pp. 45-74, 2012.

[4] M. Chinchilla, S. Arnaltes, and J. C. Burgos, "Control of permanentmagnet generators applied to variable-speed wind-energy systems 
connected to the grid," IEEE Trans. Energy Convers., vol. 21, no. 1, pp. 130-135, Mar. 2006.

[5] G. O. Cimuca, C. Saudemont, B. Robyns, and M. M. Radulescu, "Control and performance evaluation of a flywheel energy-storage system associated to a variable-speed wind generator," IEEE Trans. Ind. Electron., vol. 53, no. 4, pp. 1074-1085, Apr. 2006.

[6] L. Jian, K. T. Chau, and J. Z. Jiang, "A magnetic-geared outer-rotor permanent-magnet brushless machine for wind power generation," IEEE Trans. Ind. Appl., vol. 45, no. 3, pp. 954-962, May/Jun. 2009.

[7] A. Grauers, "Efficiency of three wind energy generator systems," IEEE Trans. Energy Convers., vol. 11, no. 3, pp. 650-657, Sep. 1996.

[8] Y. Fan, K. T. Chau, and M. Cheng, "A new three-phase doubly salient permanent magnet machine for wind power generation," IEEE Trans. Ind. Appl., vol. 42, no. 1, pp. 53-60, Jan./Feb. 2006.

[9] C. Liu, K. T. Chau, J. Z. Jiang, and L. Jian, "Design of a new outer-rotor permanent magnet hybrid machine for wind power generation," IEEE Trans. Magn., vol. 44, no. 6, pp. 1494-1497, Jun. 2008.

[10] A. J. Squarezi Filho, and E. R. Filho, "Model-based predictive control applied to the doubly-fed induction generator direct power control," IEEE Trans. Sustain. Energy, vol. 3, no. 3, pp. 398-406, Jul. 2012.

[11] K. T. Chau, C. C. Chan, and C. Liu, "Overview of permanent-magnet brushless drives for electric and hybrid electric vehicles," IEEE Trans. Ind. Electron., vol. 55, no. 6, pp. 2246-2257, Jun. 2008.

[12] J. A. Krizan, and S. D. Sudhoff, "A design model for salient permanentmagnet machines with investigation of saliency and wide-speed-range performance," IEEE Trans. Energy Convers., vol. 28, no. 1, pp. 95105, Nov. 2012.

[13] B. Sarlioglu, and T. A. Lipo, "Comparison of power production capability between doubly salient permanent magnet and variable reluctance type generators," in Proc. Int. Aegean Conf. Electrical Machines and Power Electronics, Kusadasi, Turkey, 1995, pp. 1-8.

[14] J. Zhang, M. Cheng, Z. Chen, and W. Hua, "Comparison of statormounted permanent-magnet machines based on a general power equations," IEEE Trans. Energy Convers., vol. 24, no. 4, pp. 826-834, Dec. 2009.

[15] C. Liu, K. T. Chau, and J. Z. Jiang, "A permanent-magnet hybrid brushless integrated starter-generator for hybrid electric vehicles," IEEE Trans. Ind. Electron., vol. 57, no. 12, pp. 4055-4064, Mar. 2010.

[16] R. P. Deodhar, S. Andersson, I. Boldea, and T. J. E. Miller, "The fluxreversal machine: a new brushless doubly-salient permanent-magnet machine," IEEE Trans. Ind. Electron., vol. 33, no. 4, pp. 925-934, Jul. 1997.

[17] C. X. Wang, I. Boldea, and S. A. Nasar, "Characterization of three phase flux reversal machine as an automotive generator," IEEE Trans. Energy Convers., vol. 16, no. 1, pp. 74-80, Mar. 2001.

[18] W. Zhao, J. Ji, G. Liu, Y. Du, and M. Cheng, "Design and analysis of a new modular linear flux-reversal permanent-magnet motor," IEEE Trans. Appl. Supercond., vol. 24, no. 3, p. 5200305, Jun. 2014.

[19] R. Dutta, and M. F. Rahman, "Design and analysis of an Interior permanent magnet (IPM) machine with very wide constant power operation range," IEEE Trans. Energy Convers., vol. 23, no. 1, pp. 2533, Mar. 2008.

[20] J. T. Chen, Z. Q. Zhu, and D. Howe, "Stator and rotor pole combinations for multi-tooth flux-switching permanent-magnet brushless AC machines," IEEE Trans. Magn., vol. 44, no. 12, pp. 46594667, Dec. 2008.

[21] C. H. T. Lee, K. T. Chau, C. Liu, and C. Qiu, "Design and analysis of a new multitoothed magnetless doubly-salient machine," IEEE Trans. Appl. Supercond., vol. 24, no. 3, p. 5200804, Jun. 2014.

[22] L. Xu, W. Zhao, J. Ji, G. Liu, Y. Du, Z. Fang, and Li. Mo, "Design and analysis of a new linear hybrid excited flux reversal motor with inset permanent magnets," IEEE Trans. Magn., vol. 50, no. 11, p.8202204, Nov. 2014

[23] C. H. T. Lee, K. T. Chau, C. Liu, T. W. Ching, and Fi. Li, "A HighTorque Magnetless Axial-Flux Doubly-Salient Machine for In-Wheel Direct Drive Applications," IEEE Trans. Magn., vol. 50, no. 11, p.8202405, Nov. 2014.

[24] K. T. Chau, M. Cheng, and C. C. Chan, "Nonlinear magnetic circuit analysis of a novel stator-doubly-fed doubly-salient machine," IEEE Trans. Magn., vol. 38, no. 5, pp. 2282-2384, Sep. 2002.

[25] C. H. T. Lee, C. Liu, and K. T. Chau, "A magnetless axial-flux machine for range-extended electric vehicle," Energies, vol. 7, no. 3, pp. 14831499, Mar. 2014.
[26] P. Zheng, Q. Zhao, J. Bai, B. Yu, Z. Song, and J. Shang, “Analysis and design of a transverse-flux dual rotor machine for power-split hybrid electric vehicle applications," Energies, vol. 6, no. 12, pp. 6548-6568, Dec. 2013.

[27] Y. Wang, K. T. Chau, C. C. Chan, and J. Z. Jiang, "Transient analysis of a new outer-rotor permanent-magnet brushless dc drive using circuitfield-torque coupled time-stepping finite-element method," IEEE Trans. Magn., vol. 6, no. 2, pp. 1297-1300, Mar. 2002.

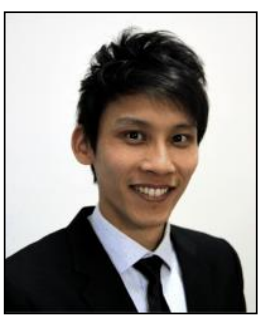

\section{BIOGRAPHIES}

Christopher H. T. Lee (StM' 2012) received the B.Eng. (First Class Honours) degree in electrical and electronic engineering from The University of Hong Kong, Hong Kong, China. Since 2011, he has been working towards the $\mathrm{Ph} . \mathrm{D}$. degree at the alma mater. During his Ph.D. study, he is co-supervised by Prof. K. T. Chau, Fellow of the IEEE, Fellow of the IET, and Fellow of the HKIE; and Prof. C. C. Chan, Fellow of Royal Academy of Engineering of UK, and Academician of Chinese Academy of

Engineering.

His research interests are Electric Machines and Drives, Renewable Energies, and Electric Vehicle Technologies. In these areas, he has published about 20 technical papers.

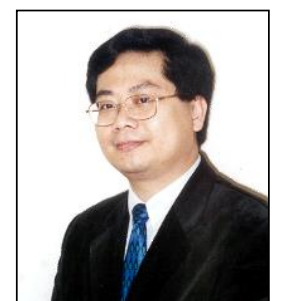

K. T. Chau (F' 2013) received his B.Sc. (Eng.) degree with First Class Honours, M.Phil. degree, and Ph.D. degree all in Electrical \& Electronic Engineering from The University of Hong Kong. He joined the alma mater in 1995, and currently serves as Professor in the Department of Electrical \& Electronic Engineering, and Director of the International Research Centre for Electric Vehicles. His main research interests are Electric Vehicle Technologies, Renewable Energy Systems, Machines and Drives. In these areas, he has published 4 books, 7 book chapters, and over 400 refereed technical papers.

He is elected Fellow of the IEEE, Fellow of the IET, and Fellow of the HKIE. He has served as chairs and organizing committee members for many international conferences, especially in the area of Electric Vehicle Technologies. Currently, he serves as Co-Editor of the Journal of Asian Electric Vehicles. Professor Chau has received many awards, including the Chang Jiang Chair Professorship, the Environmental Excellence in Transportation Award for Education, Training and Public Awareness, and the Award for Innovative Excellence in Teaching, Learning and Technology.

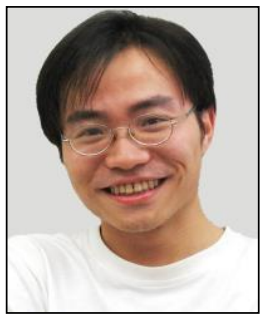

Chunhua Liu (SM' 2015) received the B.Eng., M.Eng. and Ph.D. degrees from Department of Automatic Control, Beijing Institute of Technology, China, and Department of Electrical and Electronic Engineering, The University of Hong Kong, Hong Kong, in 2002, 2005 and 2009, respectively. He is currently serving as Honorary Assistant Professor with Department of Electrical and Electronic Engineering, The University of Hong Kong, Hong Kong.

His research interests are in the areas of energy conversion, integration, and distribution, including electric drives, electric vehicles, renewable energy, vehicle to grid (V2G), microgrid, and smart grid. He currently focuses on the vehicle to grid for smart energy distribution, permanent-magnet brushless machines for sustainable energy conversion, and renewable energies for integration to smart grid. 